\title{
Unexpected Lung Metastasis After Left Hemithyroidectomy for Follicular Adenoma in a Young Adult Male: A Case Report
}

Papia Akhter, Jasmine Ferdous, Zeenat Jabin and Fatima Begum

National Institute of Nuclear Medicine \& Allied Sciences (NINMAS)

Correspondence Address: Dr Papia Akhter, Assistant Professor \& SMO,National Institute of Nuclear Medicine \& Allied Sciences (NINMAS). Block-D, BSMMU Campus, Shahbag, Dhaka-1000.Bangladesh.papia1078@gmail.com.

\begin{abstract}
Follicular neoplasms of the thyroid gland are benign follicular adenoma and follicular carcinoma. To distinguish follicular carcinoma from a follicular adenoma based on cytologic, sonographic or clinical features alone is very difficult. As follicular adenoma of the thyroid is a benign tumor usually do not metastasize. Here, a case is presented with follicular variant of papillary thyroid carcinoma (FVPTC) with lung metastasis which was treated as follicular adenoma four years back. Patient had left hemithyroidectomy for follicular adenoma and ignored to have regular follow up. He suddenly developed fever, chest pain and dry cough. CT scan evaluated a fairly big lung mass which eventually came out as metastatic follicular carcinoma. From this reported case, it is evident that regular checkup of patient with follicular adenoma should be ensured for early diagnosis of further transformation of adenoma to malignancy.
\end{abstract}

Key words: Follicular adenoma, thyroid carcinoma, metastasis.

Bangladesh J. Nucl. Med. Vol. 22 No. 2 July 2019

DOI: https://doi.org/10.3329/bjnm.v22i2.51771

\section{INTRODUCTION}

General consideration for thyroid tumor is that only malignant tumor can metastasize, and the pathogenesis is

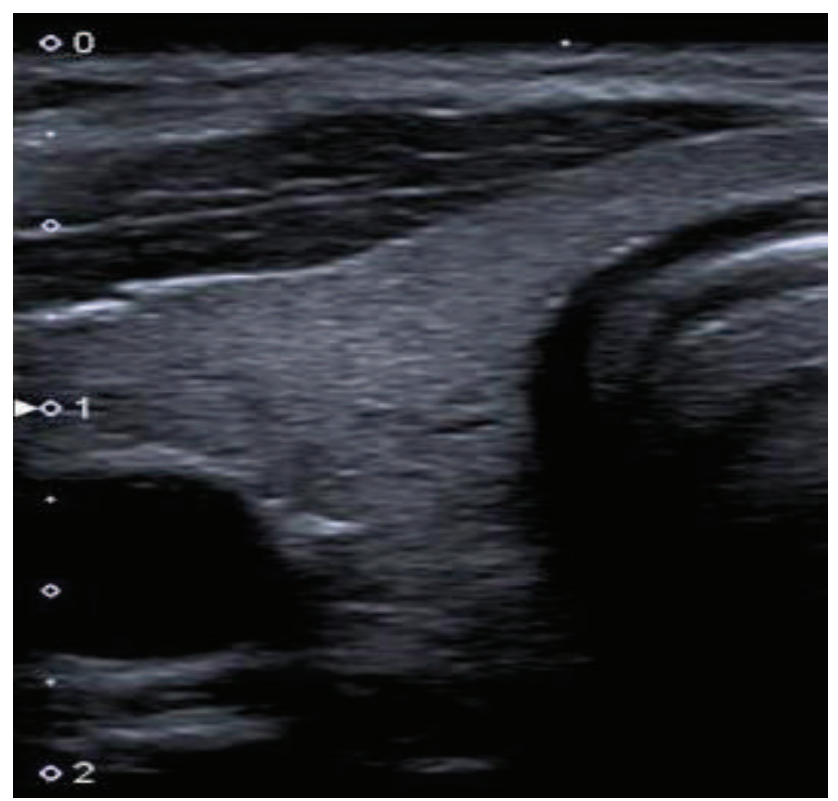

known to us. There are some benign lesions that may show distant metastasis by time, such as benign nodular goiter, follicular adenoma, and benign oncocytic follicular thyroid tumor may be due to the limitations of pathological examination (1-5). Several studies stated that encapsulated thyroid follicular tumors without histological evidence of carcinoma can metastasize (1-5); which are referred to as metastasizing adenomas (2). Here, we present a case of follicular variant of papillary thyroid carcinoma (FVPTC) that exhibited lung metastasis which was initially diagnosed as follicular adenoma.

\section{CASE REPORT}

A 32 year old male with a palpable mass on the left side of the neck visited a physician. Patient has no past medical history or risk factors for thyroid malignancy. His thyroid function tests were within normal limits. Thyroid ultrasonography (USG) revealed a predominantly solid thyroid nodule in left lobe with benign sonographic features.

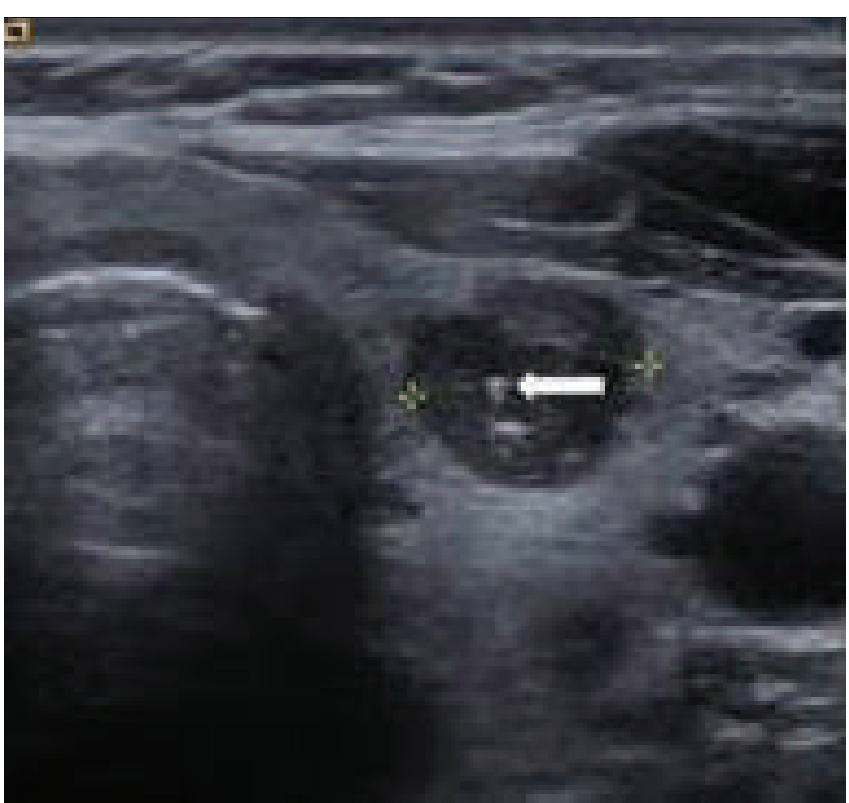

Figure 1: USG of thyroid gland showing predominantly solid nodule in left lobe \& right lobe showing uniform echo texture. 


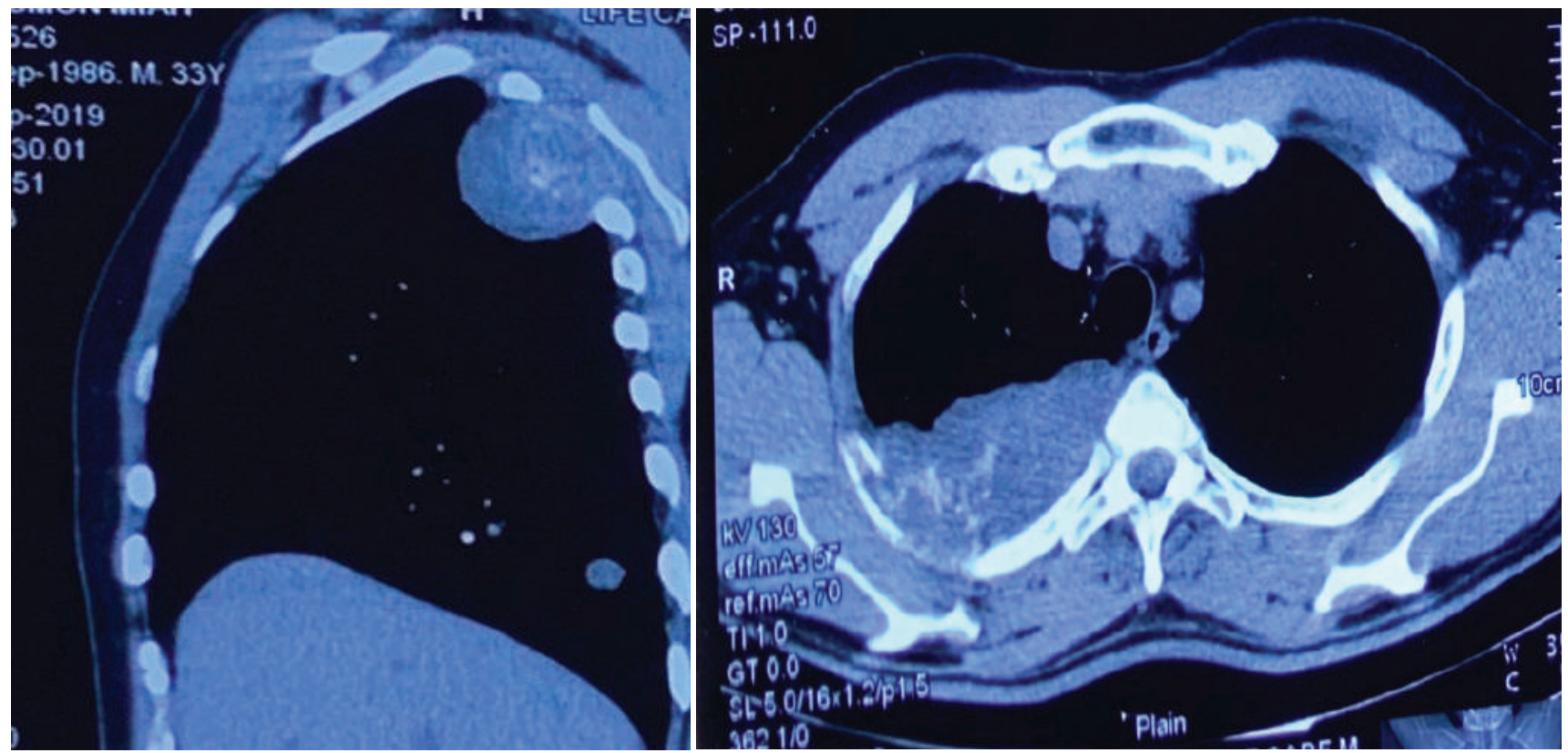

Figure 2: CT Scan of chest axial and sagittal view showing right sided lung metastasis.

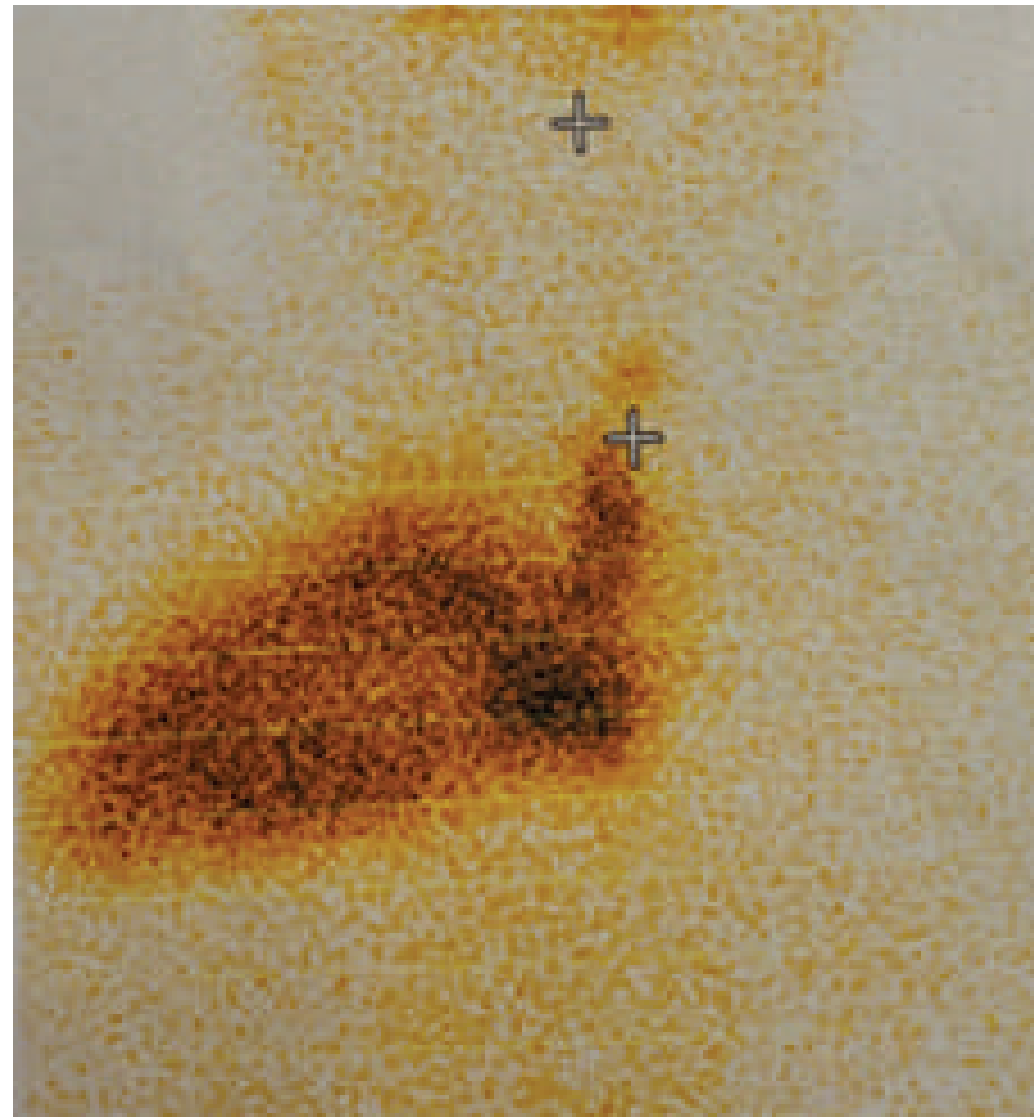

Figure 3: ${ }^{99 \mathrm{~m} T c}$ thyroid scan showing extensive uptake of radiotracer on right side of chest

Right lobe showed uniform parenchyma without any nodule. USG guided FNAC demonstrated nodular goiter without any conclusive information. For confirmation of the diagnosis and treatment of the nodule left hemithyroidectomy was done on 2016 and histopathology report showed follicular adenoma. After surgery patient did not have regular checkup for three years as he was apparently healthy. 
In 2019 patient revisited to a physician as he developed fever, chest discomfort and pain, dry cough. With all the baseline investigation CT scan of chest was done. Chest CT scan showed bone destroying mildly enhancing pleural based soft tissue density mass measuring about 9 $\mathrm{cm} \times 6 \mathrm{~cm}$ located in apical and posterior segment of right upper lobe. Then CT guided FNAC was done and revealed metastatic follicular carcinoma of the thyroid. So,completion of thyroidectomy was done. After the second surgery he was referred to NINMAS for radioactive iodine ablation (RAIA).

This time his serum thyroglobulin level was $>300 \mathrm{ng} / \mathrm{ml}$. Doing proper evaluation Nuclear Medicine specialist from NINMAS and abroad decided to treat him with external beam radiation therapy (EBRT) for symptomtic relief and volume reduction of the tumor followed by RAIA.

\section{DISCUSSION}

A follicular adenoma is a benign encapsulated tumor of the thyroid gland. It is a firm or rubbery, homogeneous, round or oval tumor that is surrounded by a thin fibrous capsule. Follicular adenoma has microscopic features that are similar to follicular carcinoma. A follicular adenoma cannot be distinguished from follicular carcinoma based on cytologic features alone. It can be distinguished on the basis of capsular invasion, vascular invasion, extrathyroidal tumor extension, lymph node metastases, or systemic metastases. A follicular neoplasm with tumor invasion into but not through the entire capsule is considered a follicular adenoma (6).

Follicular carcinoma is divided into minimally invasive and invasive variants based on morphologic criteria. Minimally invasive follicular carcinoma is an encapsulated tumor with microscopic penetration of the tumor capsule without vascular invasion (6,7). Minimally invasive follicular carcinoma is a less aggressive tumor with a disease-free survival that has been reported to be similar to a benign follicular adenoma $(8,9)$. Follicular carcinoma which was initially diagnosed as follicular adenoma was likely that areas of microinvasion were not included in the examined histological sections because of limitations in histopathological tumor sampling (3-5). The new terminology, "non-invasive follicular thyroid neoplasm with papillary-like nuclear features" (NIFTP), which has key histopathologic features [i.e., lack of invasion, follicular growth pattern, and nuclear features of papillary thyroid carcinoma (PTC)] should be considered (10). Interobserver variability may be involved in the diagnosis of FVPTC (11). According to a recent study, the diagnosis of NIFTP/encapsulated FVPTC with invasion should be made based on careful and extensive review of the tumor capsule interface to exclude minimal invasion (10). In a previous study, 5 $(0.17 \%)$ of 2,975 adenomatous thyroid nodules without pathological evidence of carcinoma exhibited metastases to lymph nodes or distant organs (1).

In this reported case, FVPTC exhibited no feature of malignancy on USG. Histopathological examination revealed thick fibrous encapsulated tumor which has corresponded to the smooth margin with a hypoechoic halo on USG. However, when assessing follicular adenomas, follicular thyroid carcinoma, and FVPTC USG examinations can be limited because these tumors tend to exhibit no malignant USG findings, unlike classic PTC (12). Follicular thyroid adenoma and carcinoma could be differentiated only on the basis of histopathology (10).

In this reported case there are some possibilities:

First, the follicular adenoma actually was an encapsulated microinvasive follicular carcinoma as morphology do not always reflect the biological behavior. Histopathology examination of this adenoma employed only $3 \mu \mathrm{m}$ thick HE sections of the paraffin tissue blocks. No step and serial section observations were performed. So, it is likely that microinvasive area (s) of follicular carcinoma may not be present in the examined sections rather was present on other sites.

Second; intact right lobe of the thyroid had follicular carcinoma. As patient was not under regular follow up and proper scrutiny was not done. Another very rare possibility is the lung tumor is lung teratoma with an exclusive differentiation into thyroid tissue, similar to struma ovarii.

\section{CONCLUSION}

In this reported case, FVPTC with lung metastasis was found after three years of surgical removal of the tumor which was initially diagnosed as follicular adenoma. From this observation it is recommended to be more meticulous to review the histopathological findings. 
Regular observation and follow up of patients with follicular adenoma should be ascertained to avoid unexpected disease outcome.

\section{REFERENCES}

1. Ito Y, Yabuta T, Hirokawa M, Fukushima M, Inoue H, Uruno T, Kihara M, Higashiyama T, Takamura Y, Miya A, Kobayashi K. Distant and lymph node metastases of thyroid nodules with no pathological evidence of malignancy: a limitation of pathological examination. Endocrine Journal. 2008:0805230148-

2. Lorenz G. Metastasizing thyroid adenoma. Zentralblatt fur Chirurgie. 1972 Sep 9;97(36):1284.

3. Terada T. Brain metastasis from thyroid adenomatous nodules or an encapsulated thyroid follicular tumor without capsular and vascular invasion: a case report. Cases Journal. 2009 Dec 1;2(1):7180.

4. Gibiezaite S, Ozdemir S, Shuja S, McCook B, Plazarte M, Sheikh-Ali M. Unexpected bone metastases from thyroid cancer. Case reports in Endocrinology. 2015 Oct;2015.

5. Boronat M, Cabrera JJ, Perera C, Isla C, Nóvoa FJ. Late bone metastasis from an apparently benign oncocytic follicular thyroid tumor. Endocrinology, Diabetes \& Metabolism Case Reports. 2013 Sep 1;2013(1).

6. D'Avanzo A, Treseler P, Ituarte PH, Wong M, Streja L, Greenspan FS, Siperstein AE, Duh QY, Clark OH. Follicular thyroid carcinoma: histology and prognosis. Cancer: Interdisciplinary International Journal of the American Cancer Society. 2004 Mar 15;100(6):1123-9.

7. Collini P, Sampietro G, Rosai J, Pilotti S. Minimally invasive (encapsulated) follicular carcinoma of the thyroid gland is the low-risk counterpart of widely invasive follicular carcinoma but not of insular carcinoma. Virchows Archiv. 2003 Jan 1;442(1):71-6.

8. van Heerden JA, Hay ID, Goellner JR, Salomao D, Ebersold JR, Bergstralh EJ, Grant CS. Follicular thyroid carcinoma with capsular invasion alone: a nonthreatening malignancy. Surgery. 1992 Dec 1;112(6):1130-8.

9. Sanders LE, Silverman M. Follicular and Hürthle cell carcinoma: predicting outcome and directing therapy. Surgery. 1998 Dec 1;124(6):967-74.

10. Nikiforov YE, Seethala RR, Tallini G, Baloch ZW, Basolo F, Thompson LD, Barletta JA, Wenig BM, Al Ghuzlan A, Kakudo K, Giordano TJ. Nomenclature revision for encapsulated follicular variant of papillary thyroid carcinoma: a paradigm shift to reduce overtreatment of indolent tumors. JAMA oncology. 2016 Aug 1;2(8):1023-9.

11. Tallini G, Tuttle RM, Ghossein RA. The history of the follicular variant of papillary thyroid carcinoma. The Journal of Clinical Endocrinology \& Metabolism. 2017 Jan 1;102(1):15-22.

12. Lee YJ, Kim DW, Park YM, Park HK, Jung SJ, Kim DH, Lee SM, Oh M. Comparison of sonographic and cytological diagnoses of solid thyroid nodules: emphasis on the discordant cases. Diagnostic cytopathology. 2015 Dec;43(12):953-9. 